\title{
БИОДЕГРАДАЦИЯ ВЕЩЕСТВА ПЕРВОГО КЛАССА ОПАСНОСТИ - БЕЛОГО ФОСФОРА
}

\author{
Миндубаев ${ }^{1}$ А.З., Бабынин ${ }^{3} Э . В .$, Бадеева ${ }^{2}$ Е.К., Минзанова ${ }^{2}$ C.T., Акосах ${ }^{3}$ Й.А. \\ ${ }^{1}$ Институт энергетики и перспективных технологий ФИЦ Каз.НЦ РАН \\ ${ }^{2}$ Институт органической и физической химии им. А.Е. Арбузова Каз.НЦ РАН \\ ${ }^{3}$ ГАОУ ВПО Казанский (Приволжский) ФУ, Казань, Россия. \\ E-mail: mindubaev-az@yandex.ru
}

https://doi.org/10.53040/9789975347204.13

\begin{abstract}
White phosphorus is one of the most dangerous environmental pollutants. However, it is used in industry and for military purposes; therefore, it is impossible to overlook the fact that this substance is constantly released into the environment. In our works, cultures of microorganisms growing in media with a content of white phosphorus up to $1 \%$ were obtained for the first time. This exceeds the TLV in wastewater by 5000 times! These cultures are unique. For the first time, cultures were grown in media containing white phosphorus as the sole source of phosphorus. In these environments, microorganisms grew without experiencing phosphorus starvation. That is, they oxidized white phosphorus to phosphate, which is necessary for vital activity! This is first ever example of the inclusion of white phosphorus in the biospheric circulation of the phosphorus element.
\end{abstract}

Key words: microorganisms, white phosphorus, Aspergillus niger AM1.

\section{Введение}

Биодеградация является одним из наиболее важных методов обезвреживания промышленных стоков, обогащенных неприродными веществами самых разнообразных классов, в том числе очень токсичными [1]. Главное преимущество биодеградации заключается в том, что при ее использовании в окружающую среду не вносятся новые химические загрязняющие агенты. На рисунке 1 продемонстрирована показательная схема усвоения токсичного биоцида в метаболическом пути, демонстрирующая совершенство биохимии микроорганизмов и изображенная на основе литературных источников [2].

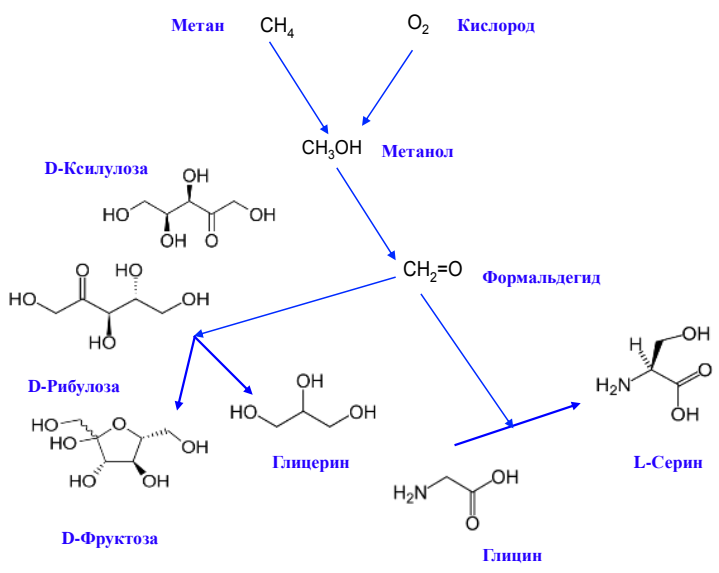

Рис.1. Включение метанола и формальдегида в состав сахаров, аминокислот и липидов в одну стадию - убедительный пример биодеградации. Окисление метана, который сам является продуктом микробного метаболизма [3] до метанола осуществляется метанотрофными бактериями [4]. Синтез серина, фруктозы или трехуглеродных сахаров из метанола и формальдегида осуществляется некоторыми метилотрофными бактериями и дрожжами. Рисунок А.3. Миндубаева 
Это является весомым фундаментальным аргументом в пользу возможности биодеградации даже самых опасных веществ, таких, как объект нашего исследования белый фосфор [5].

\section{Материалы и методы}

Нами впервые произведены посевы микроорганизмов в культуральные среды, содержащие белый фосфор в качестве единственного источника фосфора [6]. Для генетической идентификации гриба, метаболизирующего белый фосфор и отнесенного к виду Aspergillus niger, была определена нуклеотидная последовательность его регионов ITS1 и ITS2.

\section{Результаты и обсуждение}

В данных средах микроорганизмы росли и не испытывали фосфорное голодание (рис. 2). Это первый в мире пример включения белого фосфора в биосферный круговорот элемента фосфора. Самая высокая концентрация соответствует превышению ПДК белого фосфора в сточных водах в 5000 раз, а в водах хозяйственнобытового назначения - в сто миллионов раз [7]!

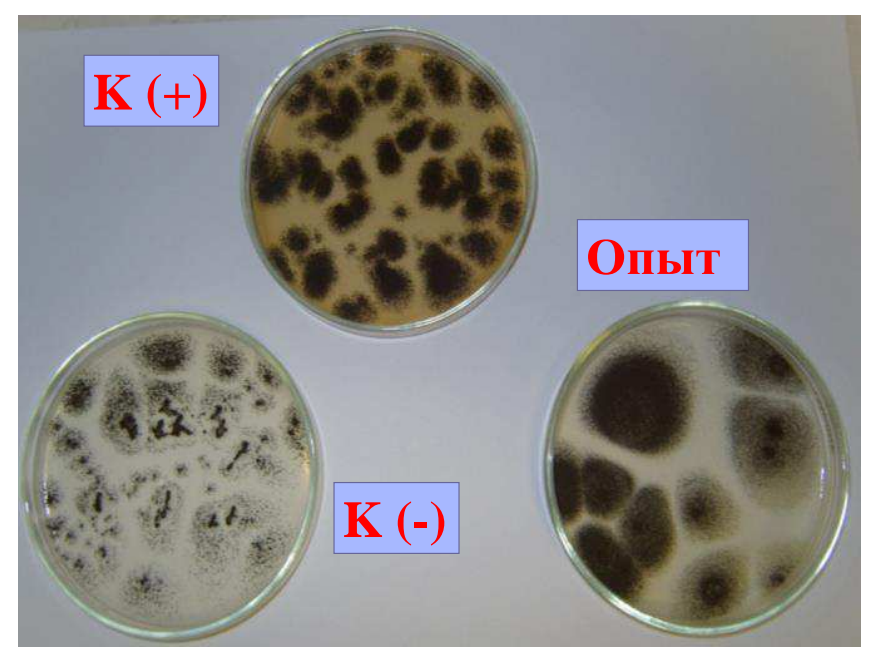

Рис.2. Посев устойчивых грибов A. niger. К(+) - среда с фосфатом: наблюдался рост 49 спорообразующих колоний A. niger. К(-) - среда без источника фосфора: в ней наблюдался рост 33 ослабленных колоний. Опыт - среда с $0.05 \%$ белого фосфора: наблюдался рост 11 крупных спорообразующих колоний A. niger. Чашки сфотографированы через шесть суток после посева.

Сравнение полученной последовательности с последовательностями базы данных GenBank с помощью системы BLAST, позволяет идентифицировать данный микроорганизм, как новый штамм A. niger. Ему мы присвоили номер A. niger AM1. Нуклеотидная последовательность штамма опубликована в базе данных GenBank, где ей присвоен номер КТ805426.

Очень интересно спонтанное появление в среде с белым фосфором культуры $A$. niger AM1 с измененной морфологией и окраской, быстрее растущей в среде с исследуемым ксенобиотиком. Возможно, это результат мутации и дальнейший этап адаптации микроорганизма к среде, содержащей белый фосфор [8]. 
Проведена оценка генотоксичности белого фосфора при помощи SOS-lux теста, которая продемонстрировала ее наличие [9]. Этот результат получен впервые - во всех найденных нами источниках сообщается об отсутствии генотоксических свойств у белого фосфора. Белый фосфор проявляет слабую мутагенную активность.

\section{Выводы}

До начала наших работ биодеградация белого фосфора (как и других его аллотропных модификаций) не была описана. Нами впервые было показано окисление элементного фосфора до фосфата - безвредного компонента всех живых клеток - и дальнейшее включение в микробную биомассу.

\section{Библиография}

1. Миндубаев А.3. Кто съел полиэтилен? // Наука и жизнь. 2018. № 4. С. 32-38.

2. Yurimoto H., Kato N., Sakai Y. Assimilation, Dissimilation, and Detoxification of Formaldehyde, a Central Metabolic Intermediate of Methylotrophic Metabolism // The Chemical Record. 2005. Vol. 5. No.6. P. 367-375. DOI: 10.1002/tcr.20056

3. Миндубаев А.З., Белостоцкий Д.Е., Минзанова С.Т., Миронов В.Ф., Алимова Ф.К., Миронова Л.Г., Коновалов А.И. Метаногенез: Биохимия, Технология, Применение // Учен.зап. Казан. ун-та. Сер. Естеств. науки. 2010. Т.152. Кн.2. С.178-191.

4. Tinberg C.E., Lippard S.J. Oxidation reactions performed by soluble methane monooxygenase hydroxylase intermediates $\mathrm{H}_{\text {peroxo }}$ and $\mathrm{Q}$ proceed by distinct mechanisms // Biochemistry. 2010. Vol. 49. P. 7902-7912._DOI: 10.1021/bi1009375.

5. Миндубаев А.З., Волошина А.Д., Валидов Ш.З., Яхваров Д.Г. Биодеградация белого фосфора // Природа. 2017. № 5.С. 29-43.

6. Миндубаев А.З., Волошина А.Д., Бабынин Э.В., Бадеева Е.К., Хаяров Х.Р., Минзанова С.Т., Яхваров Д.Г. Микробиологическая деградация белого фосфора // Экология и промышленность России. 2018. Т. 22. № 1. С. 33-37. DOI: 10.18412/18160395-2018-1-33-37

7. Mindubaev A.Z., Babynin E.V., Voloshina A.D., Saparmyradov K.A., Akosah Y.A., Badeeva E.K., Minzanova S.T., Mironova L.G. The possibility of neutralizing white phosphorus using microbial cultures // Известия НАН РК. Серия геологии и технических наук. 2019. Vol. 5. No.437. P.122-128. DOI: 10.32014/2019.2518-1491.63

8. Mindubaev A.Z., Kuznetsova S.V., Evtyugin V.G., Daminova A.G., Grigoryeva T.V., Romanova Y.D., Romanova V.A., Babaev V.M., Buzyurova D.N., Babynin E.V., Badeeva E.K., Minzanova S.T., Mironova L.G. Effect of White Phosphorus on the Survival, Cellular Morphology, and Proteome of Aspergillus niger // Applied Biochemistry and Microbiology. 2020. Vol.56. No.2. P.194-201._DOI: 10.1134/S0003683820020118

9. Миндубаев А.З., Бабынин Э.В., Бадеева Е.К., Пискунов Д.Б., Махиянов А.Н., Минзанова С.Т., Миронова Л.Г., Волошина А.Д. Генотоксичность и цитогенетическое действие белого фосфора // Известия вузов. Прикладная химия и биотехнология. 2019. T.9. №1. C. 81-94. DOI: 10.21285/2227-2925-2019-9-1-81-94 